\title{
Correlation of the severity of HRCT findings with the other hematologic parameters \& viral load in patients with confirmed COVID - 19 Infection
}

\author{
Anjali Goyal' ${ }^{1}$, Misha Antani ${ }^{2}$, Suhani Agrawal ${ }^{3}$, Chandni Gadara ${ }^{4}$, Milap D Shah ${ }^{5}$, \\ Chhaya J Bhatt ${ }^{6}$
}

${ }^{1}$ Associate Professor, 2,3,4,5 Resident, ${ }^{6}$ Professor, Department of Pathology, Smt. Nathiba Hargovandas Lakhmichand Municipal Medical College, Ahmedabad, Gujarat

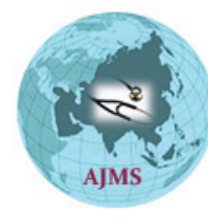

A B S T R A C T

Background: The latter half of 2019 saw the spread of a highly contagious and fatal respiratory tract disease originating in the Hubei province of Wuhan in China which was labelled as COVID 19. Although a multi organ disease, it is seen to spread through the respiratory tract with lung being the primary target. Aims and Objective: The study was conducted to correlate the severity of lung involvement as assessed by the HRCT severity, with the Viral Severity index, laboratory parameters, duration of hospital stay, viral clearance and resolution of lung symptoms. Materials and Methods: An observational retrospective study was carried out from the laboratory records of consecutive 208 patients admitted to the tertiary care hospital between March 2020 to May 2020. Results: Out of a total of 208 patients, $200(96 \%)$ recovered and $8(4 \%)$ expired. The expired patients showed a higher average age $(50.79+/-17.42 ; 62.25+/-12.37)$ years in the recovered $\&$ expired patients respectively $(p=0.06)$. A longer duration of hospital stay was seen in the expired patients $(15.05+/-9.55 \& 18.62+/-10.22)$ days in the recovered \& expired patients respectively. A low average (Hemoglobin) $\mathrm{Hb}$ values $(12.17+/-2.01 \& 10.9+/-$ $2.31) \mathrm{g} / \mathrm{dl}$ in the recovered and expired patients respectively along with a higher total WBC count was seen in the expired patients $(8.62+/-3.81 \& 16.86+/-12.79) \mathrm{k} / \mathrm{U}$ in the recovered and expired patients with a highly significant $p$ value of $<0.001$ ). Higher CT severity scores were seen in the expired patients $(10.74+/-5.57 \& 17.12+/-6.55)$ in the recovered and expired patients respectively $(p=0.0018)$. None of the expired patients had a normal D Dimer level. HRCT values and the Rising D Dimer levels tend to show a positive correlation with the disease outcome and progression. The Higher Viral severity and HRCT score was associated with a longer duration of hospital stay reflecting a higher duration of viral clearance. Conclusion: The Chest CT scores along with the laboratory parameters like the total WBC count and the D Dimer levels can together act as important parameters to monitor the Covid 19 disease course.

Keywords: Covid 19; D Dimer; HRCT; viral load

\section{INTRODUCTION}

The COVID 19 epidemic which originated in the Hubei province of Wuhan in China spread in the latter half of 2019 \& was labelled as COVID 19 \& the virus as SARS CoV 2. It was declared a Pandemic by WHO as early as in March 2020. ${ }^{1-3}$

\section{Access this article online}

Website:

http://nepjol.info/index.php/AJMS DOI: 10.3126/ajms.v12i9.38323

E-ISSN: 2091-0576

P-ISSN: 2467-9100

Copyright (c) 2021 Asian Journal of Medical Sciences

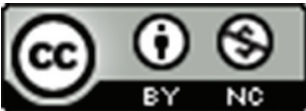

This work is licensed under a Creative Commons Attribution-NonCommercial 4.0 International License.
A massive proportion of the world population has been affected by the disease amounting to almost 19 crores cases worldwide accounting for more than 42 lacs deaths worldwide till date. India alone accounts for a massive proportion with $3 \mathrm{Cr}$ cases \& over 4.25 deaths. 
The Pandemic spread globally as a multiorgan disease, with the lung \& the respiratory tract as the primary target, with varying clinical manifestations associated with a high morbidity and mortality. ${ }^{4}$ The High-Resolution Computed Tomography (HRCT) scans has a reported high sensitivity in patients infected by SARS-CoV-2 in various studies ${ }^{4-6}$

\section{Aims and Objective}

The study was conducted to study the correlation of HRCT severity with the viral severity on RT PCR, variation of laboratory parameters $\&$ the duration of hospital stay.

\section{MATERIALS AND METHODS}

A single-centre observational retrospective analysis was done from the hospital records on 208 consecutive patients with respiratory symptoms having a confirmed COVID -19 infection confirmed by RT PCR (from the nasal \& oropharyngeal swabs) admitted to the tertiary care hospital between Mar 2020 to May 2020, after taking an approval from the Institutional Review Board (NHLIRB from the meeting held on $8^{\text {th }}$ June 2020: Dated 10/6/2020).

Out of a total of 2739 patients admitted, consecutive 241 expired patients \& 530 recovered patients were shortlisted during the study period, of which 208 (200 recovered \& 8 expired) patients were studied after applying the inclusion $\&$ the exclusion criteria. All patients with a laboratory record of Viral Severity on RTPCR, Laboratory Parameters like D Dimer levels \& an HRCT done for the respiratory symptoms following coronavirus infection, were included in the study \& the patients with an insufficient laboratory data, incomplete laboratory records or lost to follow up as they were transferred to other hospitals were excluded from the study.

The days the patients were admitted till the time they were discharged following a negative RT PCR test on two occasions was recorded as the duration of hospital stay. The duration between the RT PCR test \& HRCT scan till the outcome was recorded as the viral clearance $\&$ as the time for a resolution of the lung involvement respectively.

The HRCT scans were done on 128 Slice Philips Scanner $\&$ the findings were graded out of a total score of 25 , as $\leq$ 10(mild), 11 to 16(Moderate) \& > 16(Severe) respectively. The Viral severity was assessed on Thermo Fisher ABI 7500 \& the Ct cycles on RT PCR as Low, Moderate \& High (> 32, 24- 31, \& < 24) respectively. The Haematology Parameters taken for comparison of results was done on Siemens Advia2120i. The D Dimer levels was done on STA Compact Max3. (Normal $<0.5 \mu / \mathrm{ml}$ ). The values were recorded as $>4 \mu / \mathrm{ml}$ were analysed as exponentially high values.

A univariate and multivariate analysis on the data was done $\&$ was statistically analysed on SPSS 20.0 from IBM.

\section{RESULTS}

After Applying the Inclusion \& Exclusion criteria, the total number of patients enrolled in the study was 208 of which $200(96 \%)$ recovered \& $8(4 \%)$ expired (Table 1, Figure 1).

The expired patients showed a significant association with a higher CT severity and total WBC count along with a higher average age, increased duration of hospital stay and low Hb levels. No significant association with the Viral Severity was seen between the two groups.

The average age for the Male \& Female patients showed no significant variation (Table 2).

The average increase in HRCT values showed a significant variation $(p<0.001)$ between the mild, moderate $\&$ severe categories. A significant correlation with an increasing age,

\begin{tabular}{|c|c|c|c|c|c|c|}
\hline \multicolumn{7}{|c|}{ Total Patients $n=208$} \\
\hline & $\begin{array}{c}\text { Recovered } \\
n=200(96 \%)\end{array}$ & SD & $\begin{array}{l}\text { Expired } \\
n=8(4 \%)\end{array}$ & SD & $t$ test & $P$ value \\
\hline Age & 50.79 & 17.42 & 62.25 & 12.37 & 1.84 & 0.06 \\
\hline DOD-DOE/D & 15.05 & 9.55 & 18.62 & 10.22 & 1.03 & 0.3 \\
\hline $\mathrm{Hb}$ & 12.17 & 2.01 & 10.9 & 2.31 & 1.74 & 0.08 \\
\hline $\mathrm{TC}$ & 8.62 & 3.81 & 16.86 & 12.79 & 5.16 & $<0.001$ \\
\hline VS & 27.88 & 5.03 & 27.33 & 4.84 & 0.3 & 0.76 \\
\hline CT & 10.74 & 5.57 & 17.12 & 6.55 & 3.15 & 0.0018 \\
\hline
\end{tabular}

\begin{tabular}{|c|c|c|c|c|c|}
\hline $\begin{array}{l}\text { Females } \\
n=70\end{array}$ & SD & $\begin{array}{l}\text { Males } \\
n=138\end{array}$ & SD & $\mathrm{t}$ test & $P$ value \\
\hline 51.81 & 17.61 & 50.94 & 17.77 & 0.137 & 0.89 \\
\hline
\end{tabular}

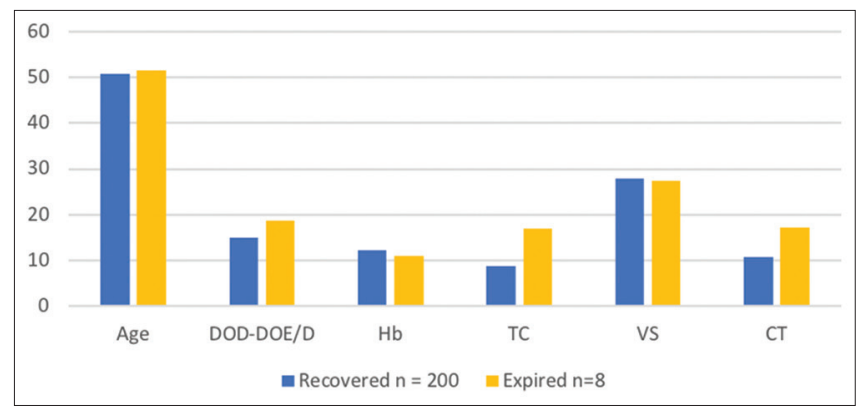

Figure 1: Comparison between the severity of parameters in the recovered and the expired patients 
total WBC count, the average duration of hospital stays, the duration of viral clearance \& the resolution of lung lesions. No correlation with the Viral severity \& the HRCT severity was seen (Table 3) (Figure 2,2a).

The Viral severity was analyzed in 131 patients. An average decrease in the $\mathrm{Ct}$ cycles reflecting an increasing viral severity was seen $(p<0.001)$. A positive correlation with an increase in the CT severity was seen. However, no correlation of the viral severity with any other parameter was seen (Table 4) (Figure 3,3a).

Comparison of variation of parameters with the viral severity in the recovered patients $(n=125)$ showed a higher average duration for viral clearance was seen in patients with a high viral severity along with a higher average age. A higher average CT severity was seen in moderate and severe viral severity in the recovered patients. However, the expired patients $(\mathrm{n}=6)$ showed a negative association with the HRCT severity (Table 5).

The D Dimer levels were analyzed in 193 patients. A lower average age, normal total WBC count, \& $\mathrm{Hb}$ levels was seen in the patients with normal D Dimer. The patients with exponentially high levels had a higher average age low Hb, High Total WBC count \&

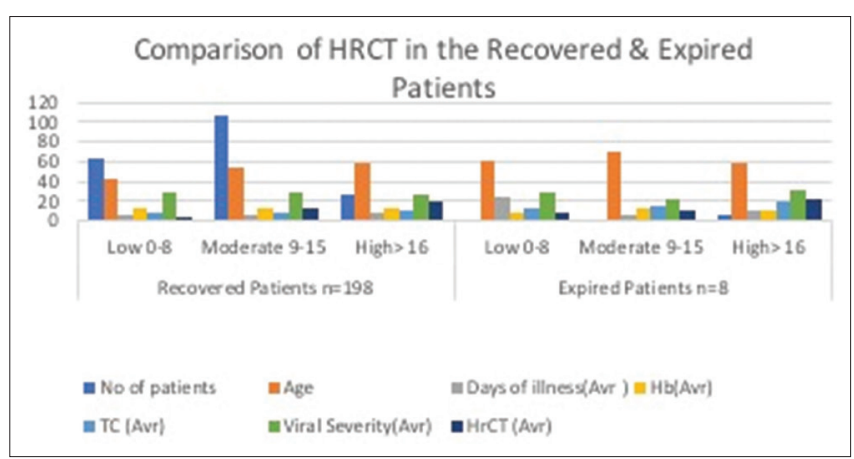

Figure 2: Comparison of HRCT in recovered and Expired patients

\begin{tabular}{|c|c|c|c|c|c|c|c|c|}
\hline \multicolumn{9}{|c|}{ Comparison of HRCT Severity with other parameters } \\
\hline \multirow{2}{*}{$\begin{array}{l}\text { Average } \\
\text { Parameters }\end{array}$} & \multicolumn{2}{|c|}{ Mild } & \multicolumn{2}{|c|}{ Moderate } & \multicolumn{2}{|c|}{ Severe } & \multirow[t]{2}{*}{$f$} & \multirow{2}{*}{$\begin{array}{c}p \\
\text { value }\end{array}$} \\
\hline & Mean & SD & Mean & SD & Mean & SD & & \\
\hline $\mathrm{Ag}$ & 3.91 & 18.09 & 54.8 & 15.46 & 56.52 & 14.67 & 10.456 & $<0$ \\
\hline Mean Vs & 28.07 & 5.26 & 27.71 & 4.13 & 27.3 & 3.86 & 0.3704 & 0.6909 \\
\hline $\begin{array}{l}\text { Ct Severity } \\
\text { /25index }\end{array}$ & 4.68 & 3.1 & 12.58 & 1.57 & 17.97 & 2.04 & 458.9 & $<0.001$ \\
\hline $\mathrm{Hb}$ & 12.33 & 1.89 & 12.02 & 1.9 & 12.15 & 1.7 & 0.553 & 0.5761 \\
\hline Tc & 7.8 & 3.73 & 8.65 & 3.86 & 10.43 & 3.48 & 6.144 & 0.0026 \\
\hline DOA-DOD/E & 12.91 & 8.88 & 15.35 & 8.59 & 18.05 & 10.62 & 4.09 & 0.0182 \\
\hline PCR-DOD/E & 11.69 & 7.79 & 14.51 & 7.31 & 18.23 & 10.51 & 8.076 & 0.0004 \\
\hline $\mathrm{HRCT}=\mathrm{DOD} / \mathrm{E}$ & 6.91 & 4.48 & 6.43 & 4.26 & 8.81 & 6.99 & 3.111 & 0.0468 \\
\hline
\end{tabular}

Increased HRCT severity. None of the patients in the expired group had a normal D Dimer level (Table 6) (Figure 4, 4a).

\section{DISCUSSION}

A comparison of the results was done with the other similar studies. A comparison of Chest CT findings in 154 patients with RT-PCR-confirmed COVID-19 pneumonia with other types of Viral pneumonia, Xiao Li et al., ${ }^{7}$ highlighted the distribution of lesions on HRCT in Covid 19 pneumonia.

Jie et al., divided the clinical features of the patients depending on the severity of the HRCT findings. Tan et al.," showed a statistically significant association between the disease severity \& the severity of the HRCT scores.

\begin{tabular}{|c|c|c|c|c|c|c|c|c|}
\hline \multicolumn{9}{|c|}{$\begin{array}{c}\text { Comparison of variation of Viral Severity with other } \\
\text { parameters }\end{array}$} \\
\hline & \multicolumn{2}{|c|}{ Mild } & \multicolumn{2}{|c|}{ Moderate } & \multicolumn{2}{|c|}{ Severe } & \multirow[b]{2}{*}{ f } & \multirow[b]{2}{*}{$p$} \\
\hline & Mean & SD & Mean & SD & Mean & SD & & \\
\hline Age & 45.7 & 17.72 & 56.22 & 15.13 & 51.29 & 16.72 & 4.582 & 0.012 \\
\hline Mean Vs & 33.5 & 1.31 & 27.87 & 1.85 & 21.87 & 2.34 & 293.46 & $<0.001$ \\
\hline $\begin{array}{l}\text { Ct Severity } \\
\text { /25index }\end{array}$ & 9.36 & 5.98 & 13.61 & 5.07 & 10.06 & 6.43 & 7.864 & 0.0006 \\
\hline $\mathrm{Hb}$ & 12.45 & 1.72 & 11.9 & 1.93 & 12.23 & 2.09 & 0.9394 & 0.3936 \\
\hline TC & 10.63 & 7.99 & 10.28 & 4.26 & 8.14 & 4.13 & 2.148 & 0.121 \\
\hline $\begin{array}{l}\text { DOA- } \\
\text { DOD/E }\end{array}$ & 14.35 & 10.19 & 16.09 & 9.72 & 14.9 & 9.55 & 0.3843 & 0.6817 \\
\hline $\begin{array}{l}\mathrm{PCR} \\
-\mathrm{DOD} / \mathrm{E}\end{array}$ & 12.16 & 9.05 & 15.87 & 8.29 & 15.51 & 9.96 & 1.91 & 0.1523 \\
\hline $\begin{array}{l}\text { HRCT- } \\
\text { DOD/E }\end{array}$ & 8.87 & 8.89 & 8.67 & 6.96 & 6.25 & 3.61 & 1.552 & 0.2158 \\
\hline
\end{tabular}

\begin{tabular}{|c|c|c|c|c|c|c|}
\hline \multicolumn{7}{|c|}{ VIRAL Severity in recovered and Expired patients $n=131$} \\
\hline & \multicolumn{3}{|c|}{ Recovered Patients $n=125$} & \multicolumn{3}{|c|}{ Expired Patients $n=6$} \\
\hline & $\begin{array}{c}\text { Severe } \\
(<24)\end{array}$ & $\begin{array}{l}\text { Moderate } \\
(24-32)\end{array}$ & $\begin{array}{l}\text { Mild } \\
(>32)\end{array}$ & $\begin{array}{c}\text { Severe } \\
(<24)\end{array}$ & $\begin{array}{c}\text { Moderate } \\
(24-32)\end{array}$ & $\begin{array}{l}\text { Mild } \\
(>32)\end{array}$ \\
\hline $\begin{array}{l}\text { No of } \\
\text { Patients }\end{array}$ & 29 & 66 & 30 & 2 & 3 & 1 \\
\hline Age & 50 & 50.88 & 45 & 70 & 63.6 & 77 \\
\hline $\begin{array}{l}\mathrm{PCR} \\
\text {-DOD/E }\end{array}$ & 16 & 15.46 & 12.31 & 6 & 11 & 8 \\
\hline $\mathrm{Hb}$ & 12.5 & 11.89 & 12.59 & 12 & 11 & 8.2 \\
\hline $\mathrm{TC}$ & 7.71 & 9 & 9.46 & 14.36 & 15.53 & 45.86 \\
\hline Mean VS & 21.86 & 28 & 33.53 & 22 & 28.6 & 34 \\
\hline $\begin{array}{l}\text { CT } \\
\text { Severity } \\
/ 25 \text { Index } \\
\text { (Avr) }\end{array}$ & 10.03 & 12.83 & 8.86 & 10.5 & 17.6 & 24 \\
\hline
\end{tabular}




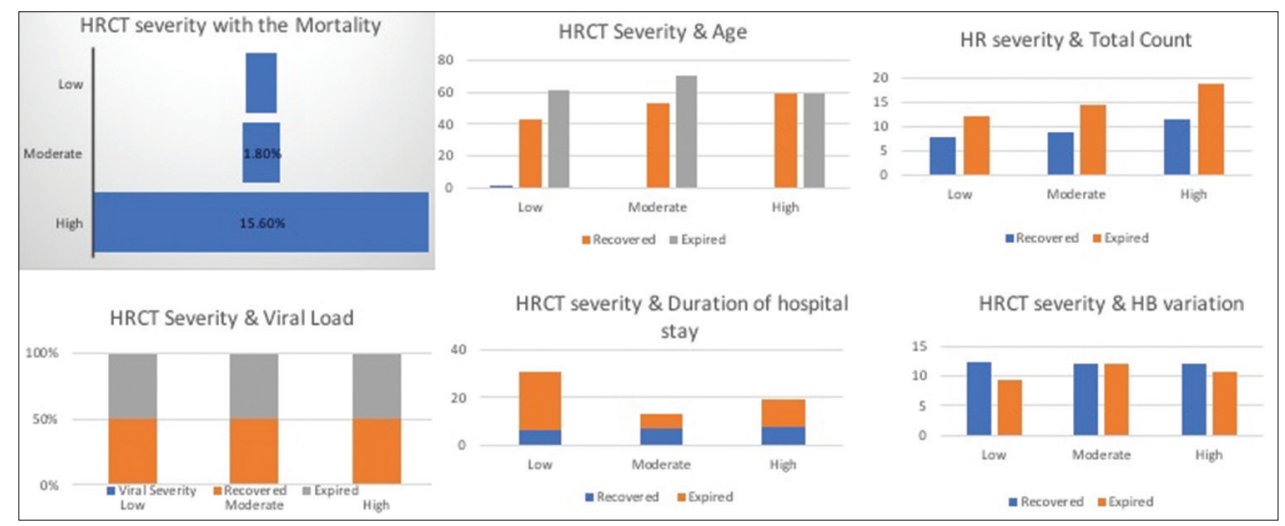

Figure 2a: HRCT variation with various parameters

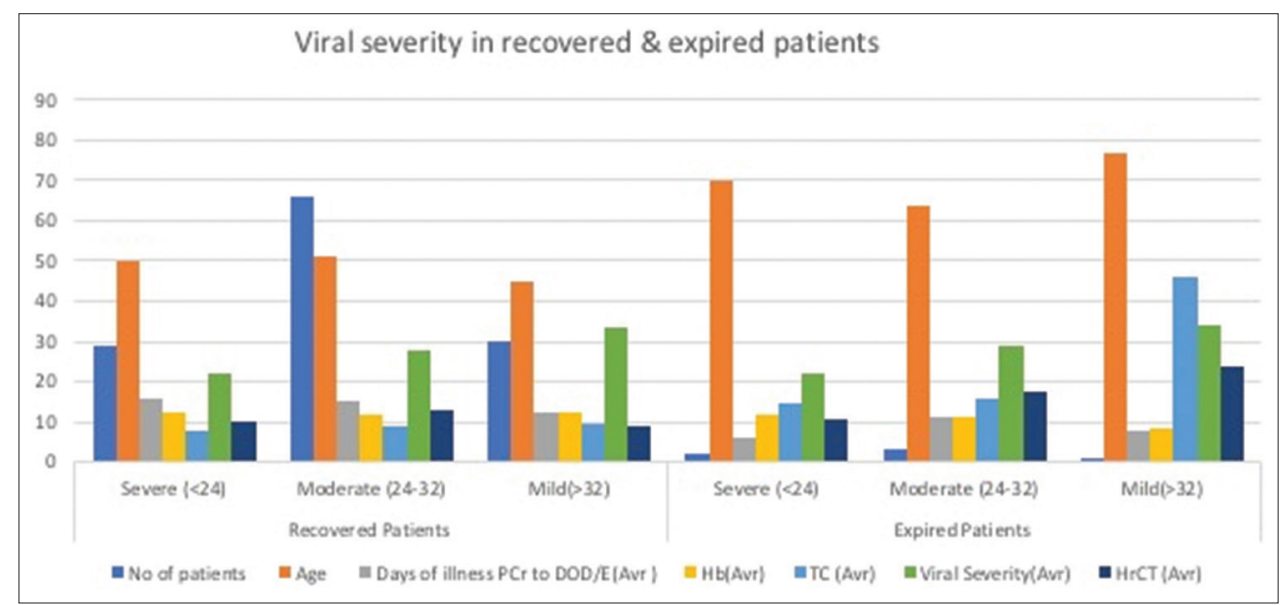

Figure 3: Comparison of Viral severity in recovered and expired patients

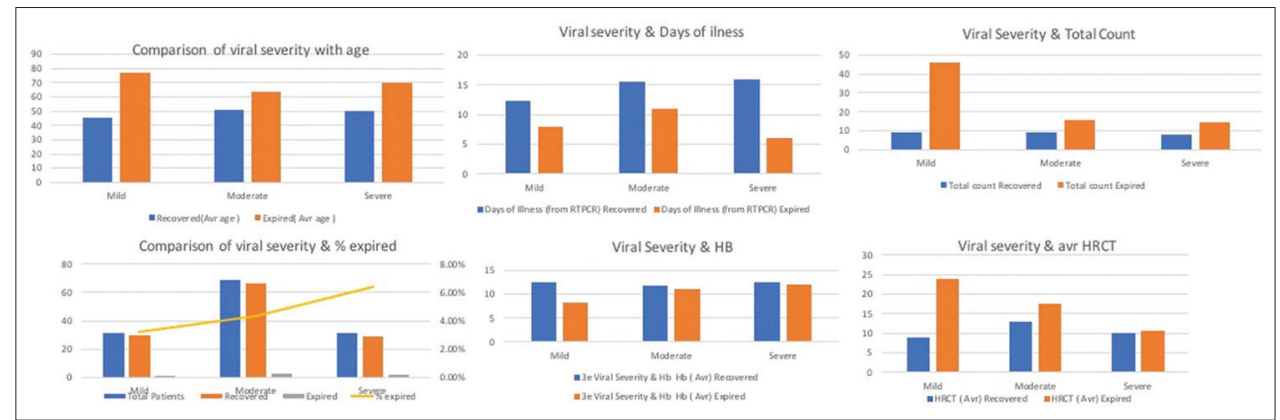

Figure 3a: Variation of Viral severity with various parameters

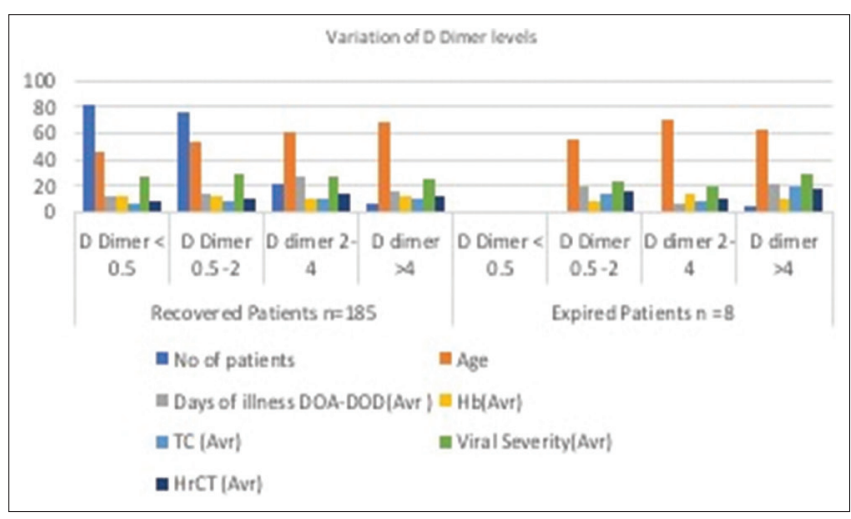

Figure 4: Variation of D Dimer levels with various parameters
Larici et al., ${ }^{10}$ observed that the HRCT scans should be considered as the modality of choice in assessing the differential diagnosis with other infectious and noninfectious lung diseases.

Study by Pan et al., ${ }^{6}$ concluded that an HRCT evaluation was critical for an early detection, and evaluation of the disease severity in COVID 19 pneumonia.

In a study by Dai et al., ${ }^{11}$ the authors observed that, the epidemiologic history and clinical characteristics of Covid 19 patient were more critical for the diagnosis than the HRCT scans alone. 


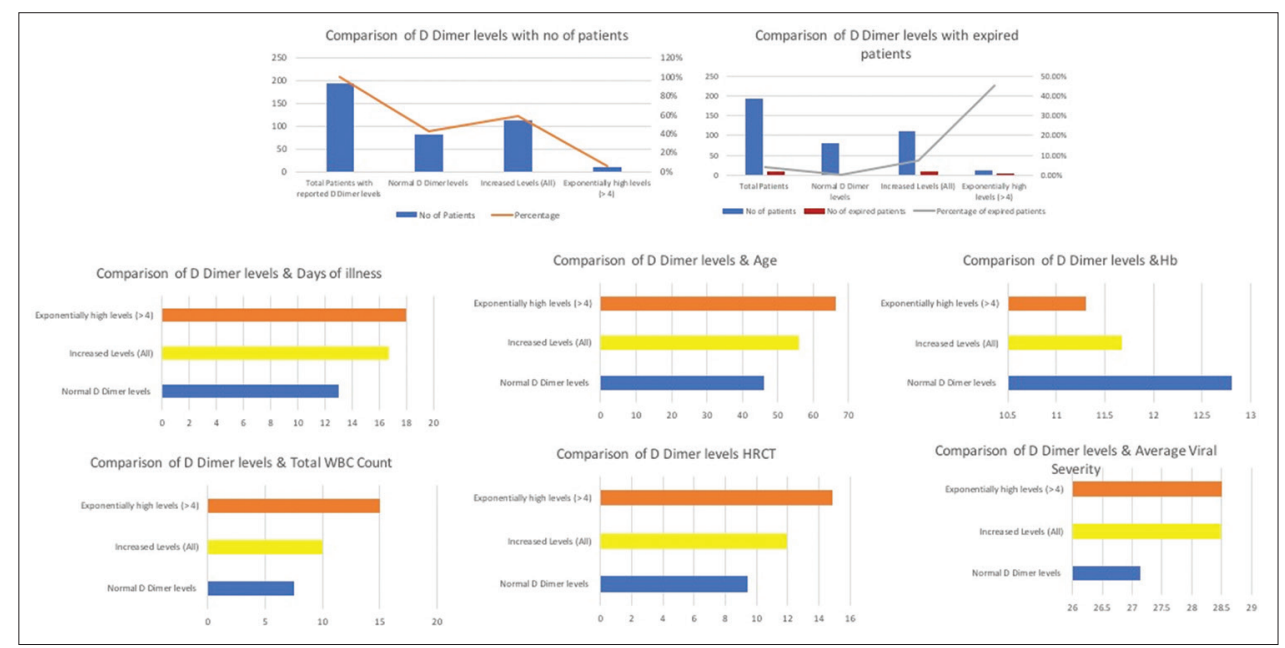

Figure 4a: Comparison of D Dimer levels in the recovered and expired patients

\begin{tabular}{|c|c|c|c|c|c|c|}
\hline \multicolumn{7}{|c|}{ Comparison of parameters with a variation of D Dimer levels } \\
\hline & \multicolumn{2}{|c|}{ Normal } & \multicolumn{2}{|c|}{ Increased } & \multirow[b]{2}{*}{$f$} & \multirow[b]{2}{*}{$\mathbf{p}$} \\
\hline & Mean & SD & Mean & SD & & \\
\hline NO OF PATIENTS & \multicolumn{2}{|c|}{81} & \multicolumn{2}{|c|}{101} & & \\
\hline AGE & 45.93 & 15.37 & 56.03 & 16.22 & 14.094 & $<0.001$ \\
\hline MEAN VS & 27.14 & 4.91 & 28.49 & 3.93 & 2.386 & 0.0946 \\
\hline $\begin{array}{l}\text { CT SEVERITY } \\
\text { /25INDEX }\end{array}$ & 9.44 & 5.28 & 11.93 & 5.77 & 6.153 & 0.0025 \\
\hline $\mathrm{Hb}$ & 12.81 & 1.6 & 11.67 & 1.86 & 10.386 & $<0.001$ \\
\hline TC & 7.52 & 3.2 & 9.98 & 5.38 & 12.77 & $<0.001$ \\
\hline DOA-DOD/E & 13.34 & 6.35 & 16.66 & 11.19 & 3.33 & 0.0378 \\
\hline PCR -DOD/E & 13.28 & 6.54 & 15.57 & 10 & 1.566 & 0.2115 \\
\hline HRCT-DOD/E & 6.5 & 3.81 & 8.02 & 6.99 & 2.441 & 0.0897 \\
\hline
\end{tabular}

Zhang et al., ${ }^{12}$ proposed a higher Sensitivity of the HRCT scans in the diagnosis of Covid 19 pneumonia.

A study by Liu et al., ${ }^{13}$ showed that the higher HRCT scores is positively correlated with the days of Viral clearance with a median of 12-14 days from the peak scores.

Lulu Gao et al., ${ }^{14}$ suggested that the imaging manifestations of the early-stage coronavirus disease were mild and atypical and need to be followed up with the laboratory examination. Cao et al., ${ }^{15}$ concluded that an elevated CT score along with an older age were strong predictors of mortality.

Chen et al., ${ }^{16}$ concluded that the HRCT scans had a more severe involvement in older patients ( $>60$ years of age. Jie Zhang et al., ${ }^{17}$ observed the chest CT score in COVID-19 infection has a positive association with the WBC count, acute phase reactants \& an abnormal coagulation function. In their study Y Wang et al., ${ }^{18}$ observed that the temporal changes on CT might indicate the recovery or progression of illness. Marco et al., ${ }^{6}$ concluded that a score of $>18$ was critical for predicting the mortality in both the univariate and the multivariate analysis and that the CT score was significantly correlated with the D Dimer levels.

In the studies comparing the D Dimer levels with the HRCT scores and disease severity, Li et al., ${ }^{5}$ concluded that the Mortality rate of COVID-19 infection showed an increase with an increasing CT score, and an increasing D Dimer level. Wang et al., ${ }^{19}$ showed that the D Dimer levels may predict the severity of inflammation in Covid-19 pneumonia. Ian Lorentt et al., ${ }^{20}$ observed that the Patients with a COVID-19 infection and pulmonary embolus had higher D-dimer levels than those without pulmonary embolus. thereby indicating an activation of blood coagulation as a part of systemic inflammatory response initiated by the virus.

In the studies comparing the viral severity with the HRCT scores, Wei Zhao et al., ${ }^{21}$ observed that the viral load of COVID 19 is negatively correlated with the HRCT values Long et al., ${ }^{22}$ observed that RT PCR may produce a higher percentage of false negative results compared to HRCT.

\section{Limitations of the study}

There are several shortfalls that can influence the outcome of the study. The pandemic spread enormously within the community and hence the flow of the patients into the hospital might not be random. Though we analysed the data of 2739 COVID-19 positive patients, the selection criteria lead us to a cohort of only 208 patients which is too small. A comprehensive study showing a comparison of the disease progression with the changing trends associated with each wave of the infection would give a better scientific perspective and serve as a guide for the disease progression. 


\section{CONCLUSION}

A comparison of the various studies demonstrates a similar pattern of the variation of various parameters. Hence, we can summarise that the HRCT values and the Rising D Dimer levels tend to show a positive correlation with the disease outcome and progression while no significant correlation of the disease with the Viral severity was seen. A higher Age (60-65 years) is associated with a higher mortality which correlates with other studies on the disease. Of particular significance is the observation that the $\mathrm{D}$ Dimer levels were not normal in any of the expired patients, which underscores the significance of D Dimer levels in monitoring the disease progression. The Higher Viral severity was associated with a longer duration of hospital stay reflecting a higher duration of morbidity.

The average duration of hospital stay was higher in the patients with a higher HRCT score $(\mathrm{p}=0.05)$, thus showing a correlation with the Viral Clearance.

Hence, we can conclude that the important parameters to monitor the Covid 19 disease course are the Chest CT scores along with the laboratory parameters like the Total WBC count \& the D Dimer levels. An increasing age remains a high-risk factor for mortality in the illness. It can be implied from the study that the Viral Severity on RT PCR does not correlate with the disease severity and outcome. The most significant association with the disease severity and prognosis was seen with the HRCT scores, Total WBC count and raised D -Dimer levels. The duration of the hospital stay shows a significant association with rising HRCT severity.

\section{ACKNOWLEDGEMENT}

The authors take this opportunity to thank Department of Pathology, Microbiology \& Radiology for their support for this study. We also acknowledge the help of Dr Hemant Tiwari from the PSM department for his help in the statistical analysis of the manuscript.

\section{REFERENCES}

1. Singhal T. A Review of Coronavirus Disease-2019 (COVID-19). Indian J Pediatr. 2020;87(4):281-286. https://doi.org/10.1007/s12098-020-03263-6

2. Huang C, Wang Y, Li X, Ren L, Zhao J, Hu Y, et al. Clinical features of patients infected with 2019 novel coronavirus in Wuhan, China. Lancet. 2020;395(10223):497-506. https://doi.org/10.1016/S0140-6736(20)30183-5

3. Li L-Q, Huang T, Wang Y-Q, Wang Z-P, Liang Y, Huang T-B, et al. COVID-19 patients' clinical characteristics, discharge rate, and fatality rate of meta-analysis. J Med Virol. 2020;92(6):577-583. https://doi.org/10.1002/jmv.25757

4. Francone M, lafrate F, Masci GM, Coco S, Cilia F, Manganaro L, et al. Chest CT score in COVID-19 patients: correlation with disease severity and short-term prognosis. Eur Radiol. 2020; 1-10.

https://doi.org/10.1007/s00330-020-07033-y

5. Li L, Yang L, Gui S, Pan F, Ye T, Liang B, et al. Association of clinical and radiographic findings with the outcomes of 93 patients with COVID-19 in Wuhan, China. Theranostics. 2020;10(14):6113-121.

https://doi.org/10.7150/thno.46569

6. Pan Y, Guan H, Zhou S, Wang Y, Li Q, Zhu T, et al. Initial CT findings and temporal changes in patients with the novel coronavirus pneumonia (2019-nCoV): a study of 63 patients in Wuhan, China. Eur Radiol. 2020;30(6):3306-3309. https://doi.org/10.1007/s00330-020-06731-x

7. Li X, Fang $X$, Bian $Y$ and Lu J. Comparison of chest CT findings between COVID-19 pneumonia and other types of viral pneumonia: a two-center retrospective study. Eur Radiol. 2020;30(10):5470-5478.

https://doi.org/10.1007/s00330-020-06925-3

8. Zhang J, Meng G, Li W, Shi B, Dong H, Su Z, et al. Relationship of chest CT score with clinical characteristics of 108 patients hospitalized with COVID-19 in Wuhan, China. Respir Res. 2020;21(1):180.

https://doi.org/10.1186/s12931-020-01440-x

9. Tan G, Lian X, Zhu Z, Wang Z, Huang F, Zhang Y, et al. Use of Lung Ultrasound to Differentiate Coronavirus Disease 2019 (COVID-19) Pneumonia from Community-Acquired Pneumonia. Ultrasound in Medicine \& Biology. 2020;46(10):2651-2658. https://doi.org/10.1016/j.ultrasmedbio.2020.05.006

10. LariciAR, Cicchetti G, Marano R, Merlino B, Elia L, Calandriello L, et al. Multimodality imaging of COVID-19 pneumonia: from diagnosis to follow-up. A comprehensive review. European Journal of Radiology. 2020; 131:109217. https://doi.org/10.1016/j.ejrad.2020.109217

11. Dai H, Zhang X, Xia J, Zhang $T$, Shang $Y$, Huang R, et al. Highresolution Chest CT Features and Clinical Characteristics of Patients Infected with COVID-19 in Jiangsu, China. International Journal of Infectious Diseases. 2020; 95:106-112. https://doi.org/10.1016/j.ijid.2020.04.003

12. Zhang S, Li H, Huang S, You W and Sun H. High-resolution computed tomography features of 17 cases of coronavirus disease 2019 in Sichuan province, China. Eur Respir J. 2020;55(4):2000334.

https://doi.org/10.1183/13993003.00334-2020

13. Liu X, Zhou H, Zhou Y, Wu X, Zhao Y, Lu Y, et al. Temporal radiographic changes in COVID-19 patients: relationship to disease severity and viral clearance. Sci Rep. 2020;10(1):10263. https://doi.org/10.1038/s41598-020-66895-w

14. Gao L and Zhang J. Pulmonary High-Resolution Computed Tomography (HRCT) Findings of Patients with Early-Stage Coronavirus Disease 2019 (COVID-19) in Hangzhou, China. Med Sci Monit. 2020;26. https://doi.org/10.12659/MSM.923885

15. Cao Y, Han X, Gu J, Li Y, Liu J, Alwalid O, et al. Prognostic value of baseline clinical and HRCT findings in 101 patients with severe COVID-19 in Wuhan, China. Sci Rep. 2020;10(1):17543. https://doi.org/10.1038/s41598-020-74497-9

16. Chen Z, Fan H, Cai J, Li Y, Wu B, Hou Y, et al. High-resolution computed tomography manifestations of COVID-19 infections in patients of different ages. European Journal of Radiology. 2020; 
126:108972.

https://doi.org/10.1016/j.ejrad.2020.108972

17. Zhang J, Meng G, Li W, Shi B, Dong H, Su Z, et al. Relationship of chest CT score with clinical characteristics of 108 patients hospitalized with COVID-19 in Wuhan, China. Respir Res. 2020;21(1):180.

https://doi.org/10.1186/s12931-020-01440-x

18. Wang Y, Dong C, Hu Y, Li C, Ren Q, Zhang X, et al. Temporal Changes of CT Findings in 90 Patients with COVID-19 Pneumonia: A Longitudinal Study. Radiology. 2020;296(2): E55-E64. https://doi.org/10.1148/radiol.2020200843

19. Wang L, Yang L, Bai L, Huang $Z$ and Peng Y. Association between $\mathrm{D}$-dimer level and chest CT severity score in patients with SARS-COV-2 pneumonia. In Review; 2020; https://doi.org/10.21203/rs.3.rs-108631/v1

20. Léonard-Lorant I, Delabranche X, Séverac F, Helms J, Pauzet C, Collange $\mathrm{O}$, et al. Acute Pulmonary Embolism in Patients with COVID-19 at CT Angiography and Relationship to d-Dimer Levels. Radiology. 2020;296(3): E189-E191. https://doi.org/10.1148/radiol.2020201561

21. Zhao W, He L, Tang H, Xie X, Tang L, and Liu J. The Relationship Between Chest Imaging Findings and the Viral Load of COVID-19. Front Med. 2020; 7:558539. https://doi.org/10.3389/fmed.2020.558539

22. Long $\mathrm{C}, \mathrm{Xu} \mathrm{H}$, Shen $\mathrm{Q}$, Zhang X, Fan B, Wang C, et al. Diagnosis of the Coronavirus disease (COVID-19): rRT-PCR or CT? Eur J Radiol. 2020; 126:108961.

https://doi.org/10.1016/j.ejrad.2020.108961

Authors Contribution:

AG- Concept and Design, Intellectual content, Literature search, Data/Specimen Acquisition, Data Analysis, Statistical Analysis, Manuscript Preparation and Editing, Manuscript Review; MA- Literature search, Data/Specimen Acquisition; SA- Literature search, Data/Specimen Acquisition, Data Analysis; CG- Literature search, Data/Specimen Acquisition, Data Analysis; MS- Data/Specimen Acquisition, Data Analysis, Statistical Analysis; CB- Literature search, Data/Specimen Acquisition, Data Analysis

Work attributed to:

Smt NHL Medical College and Sardar Vallabhbhai Hospital Ahmedabad Gujrat

Orcid ID:

Dr Anjali Goyal- (i) https://orcid.org/0000-0002-1945-0322

Dr Misha Antani- (1) https://orcid.org/0000-0002-8260-4611

Dr Suhani Agrawal- (D) https://orcid.org/0000-0002-7341-308X

Dr Chandni Gadara- (1) https://orcid.org/0000-0003-2159-8905

Dr Milap Shah- (1) https://orcid.org/0000-0002-0155-1598

Source of Support: Nil, Conflict of Interest: None declared. 